\title{
AS DIMENSÕES DE VARIAÇÃO DAS LÍNGUAS NAS AULAS DE LÍNGUA ITALIANA EM CONTEXTO UNIVERSITÁRIO: DA GRAMÁTICA À PRAGMÁTICA
}

\author{
The Dimensions of Linguistic Variation in the Italian Classes at University: From \\ Grammar to Pragmatics
}

\author{
Bruna Maia Rocha AFLALO, USP ${ }^{1}$ \\ Bernardo Santos AFLALO, ITA ${ }^{2}$
}

\begin{abstract}
RESUMO: Este trabalho tem como objetivo verificar se, além da sintaxe, da semântica e de outros pontos gramaticais, os estudantes de duas disciplinas de língua italiana da Universidade de São Paulo refletem também sobre a produção de mensagens adequadas aos vários contextos aos quais são expostos em língua italiana. A partir de um esquema proposto por Berruto (1993) para o grau de formalidade/informalidade de uma série de expressões que designam o verbo "morire" (morrer em italiano), foi feito um estudo para verificar se além de conhecerem o significado das expressões os alunos conheciam também os contextos em que tais expressões deveriam ser usadas. A partir dos resultados, foram conduzidas análises estatísticas com a utilização do software R para a validação dos dados. Comparando diretamente as médias obtidas entre as duas turmas, foi notado um aumento substancial na quantidade de expressões em conformidade com a referência de Berruto da turma que havia estudado a língua italiana por 1 ano para a turma que a havia estudado por 3 anos. Tal aumento evidencia, para a amostra considerada, a melhora da competência pragmática dos estudantes com o aumento de anos de estudo da língua.
\end{abstract}

PALAVRAS-CHAVE: Pragmática; Dimensões de Variação Linguística; Língua Italiana.

ABSTRACT: This paper verifies if, besides syntax, semantics and other grammatical points, the students of two disciplines of Italian language from the University of São Paulo are aware of the production of messages that are appropriate to the various contexts to which they are exposed in Italian language. Based on a scheme proposed by Berruto (1993) to the degree of formality/informality of a number of expressions that designate the verb "morire" (to die in Italian), a study has been conducted to verify if besides of knowing the meaning of the expressions the students knew also the contexts in which the expressions should be used. Statistics analyses were carried out using the software $\mathrm{R}$, in order to validate the results. The study compared two classes with different years of study of Italian language, the first one with one year and the second one with three years of experience. For the second class, it has been noticed a significant increase in the number of expressions in accordance to Berruto scheme, which highlights, to the sample considered, the improvement of the pragmatic competence of the students with the increase of years of study.

\footnotetext{
${ }^{1}$ Doutoranda em Língua, Literatura e Cultura Italianas pela Universidade de São Paulo (USP).

${ }^{2}$ Mestrando em em Engenharia Aeronautica.
} 
KEY WORDS: Pragmatics; Dimensions of Linguistic Variation; Italian.

\section{INTRODUÇÃO}

O objetivo da aprendizagem de uma língua estrangeira não é simplesmente saber produzir mensagens gramaticalmente corretas, mas saber produzir mensagens eficazes e adequadas aos vários contextos e situações comunicativas. Dessa forma, é extremamente necessário que os alunos de língua italiana em contexto universitário reflitam sobre o que é um uso adequado ou não da língua, de modo a evitar situações constrangedoras em seu desempenho em língua estrangeira.

O objetivo deste trabalho é verificar se, além da sintaxe, da semântica, da fonologia e de outros pontos gramaticais, os estudantes de dois dos cursos de língua italiana da Universidade de São Paulo (USP) refletem também sobre a produção de mensagens adequadas aos vários contextos aos quais são expostos em língua italiana.

\section{AS DIMENSÕES DE VARIAÇÃO DA LÍNGUA}

Antes de passar à metodologia e aos resultados deste trabalho se faz necessário mencionar quais são as dimensões que influenciam as mudanças de uma língua. Tais dimensões de variação são: variação diacrônica, variação diatópica, variação diafásica, variação diamésica e variação diastrática.

A variação diacrônica diz respeito à transformação e à evolução da língua ao longo do tempo. Isso quer dizer que a língua italiana falada décadas e séculos atrás pode apresentar diferenças em relação à língua italiana falada hoje. Um exemplo disso é que hoje o pronome pessoal "Voi" não é usado como forma de cortesia como era usado tempos atrás $^{3}$. Um exemplo do uso de "Voi" como forma de cortesia pode ser encontrado na obra $I$ Promessi Sposi ${ }^{4}$, obra na qual os noivos Renzo e Lucia se tratam por "Voi” mesmo depois do casamento:

Lucia però, non che trovasse la dottrina falsa in sé, ma non n'era soddisfatta; le pareva, così in confuso, che ci mancasse qualcosa. A forza di sentir ripetere la stessa canzone, e di pensarci sopra ogni volta, «e io», disse un giorno al suo moralista, «cosa volete che abbia imparato? Io non sono andata a cercare i guai: son loro che sono venuti a cercare me. Quando non voleste dire», aggiunse, soavemente sorridendo, «che il mio sproposito sia stato quello di volervi bene, e di promettermi a voi».

\footnotetext{
${ }^{3}$ Hoje em dia se usa o pronome pessoal "Lei" como forma de cortesia.

${ }^{4}$ Manzoni, A. (1827).
} 
A variação diatópica se relaciona à mudança que a língua pode sofrer de acordo com o local em que é falada: a língua italiana dos toscanos pode variar em relação à língua italiana dos romanos, dos calabreses etc. Tal diferença pode referir-se à entonação, à escolha lexical e assim por diante.

A variação diafásica ${ }^{5}$ é ligada à situação comunicativa e aos objetivos do falante ao emitir uma mensagem. Esta dimensão de variação é importantíssima para os alunos de línguas estrangeiras, já que o uso inadequado da língua em alguns contextos (ou seja, o descaso com a variação diafásica da língua) pode criar situações embaraçosas (um pode pensar que o outro é mal educado quando este usa uma linguagem muito informal em um contexto formal ou ainda pode pensar que fala de maneira estranha e pedante quando este usa uma linguagem formal em um contexto informal) e prejudicar a eficácia da mensagem que se quer passar.

A variação diastrática é ligada às condições sócio-econômicas e culturais dos falantes. Um exemplo: os jovens possuem uma linguagem diferente dos adultos, os falantes cultos possuem uma linguagem diferente de falantes sem tanta instrução etc.

Por fim, a variação diamésica é ligada à mudança da língua de acordo com o meio físico empregado, ao canal através do qual a linguagem é transmitida (o ar, a folha de papel etc) ${ }^{6}$.

Explicitadas todas as dimensões de variação das línguas, o trabalho, a partir da próxima seção, concentra-se na variação diafásica entre registros de fala formais e informais.

\section{A VARIAÇÃO DIAFÁSICA E O CONTINUUM FORMAL/INFORMAL}

Podemos dizer que a variedade diafásica por excelência é o chamado "registro". O conceito de registro utilizado neste trabalho é o conceito apresentado por Berruto (1993, p.70) "variedade diafásica dependente primariamente do caráter da interação e do papel recíproco assumido por falante (ou escritor) e destinatário".

Para que seja determinado o registro, alguns fatores determinantes são: o grau de formalidade e informalidade da situação comunicativa e o grau de atenção e controle que o falante coloca na programação de sua produção linguística Pode-se dizer que o parâmetro

\footnotetext{
5 A variação diafásica será abordada novamente na seção 3 deste trabalho. Para exemplos, ver Berruto (1987).

${ }^{6}$ Em relação ao confronto entre as diamesias falada e escrita, ver Halliday (1985), Berruto (1993) e Berretta (1994).
} 
determinante para que o registro seja individualizado é a escala de formalidade, ou seja, a escala de maior ou menor formalidade da situação e o consequente maior ou menor controle que os falantes colocam na interação.

Formal e informal representam dois extremos do eixo diafásico: a produção linguística é mais formal quando é mais controlada e menos formal quando menos controlada. Assim, em uma situação comunicativa formal, os falantes apresentam uma produção linguística mais controlada e fazem uso de expressões e termos que não seriam usados em situações em que o controle da produção linguística fosse menor.

Saber determinar se uma expressão é usada em contextos formais ou informais é muito importante para os aprendizes de uma língua estrangeira, já que usar expressões informais em contextos formais pode soar mal educado aos ouvidos de falantes nativos, ao passo que usar expressões formais em contextos informais pode soar pedante ou estranho. O que é certo é que usar expressões inadequadas ao contexto comunicativo (ou seja, usar expressões que não são diafasicamente apropriadas) é uma falha que, mesmo não gerando problemas de comunicação intrinsecamente linguísticos, geram estranhamentos ou mal entendidos pragmáticos. Daí a importância da aquisição das regras pragmáticas que gerenciam o uso dessas expressões, já que os erros pragmáticos parecem ser menos perdoados do que os erros intrinsecamente linguísticos.

As escolhas lexicais apresentam uma relevância especial para a variação diafásica, já que algumas palavras ou expressões são evitadas em contextos formais enquanto são tranquilamente usadas em contextos familiares e outros contextos informais. Um exemplo de escolha lexical foi utilizado por Berruto (1993, p. 72) para ilustrar a natureza da variação de registro da qual se fala acima:

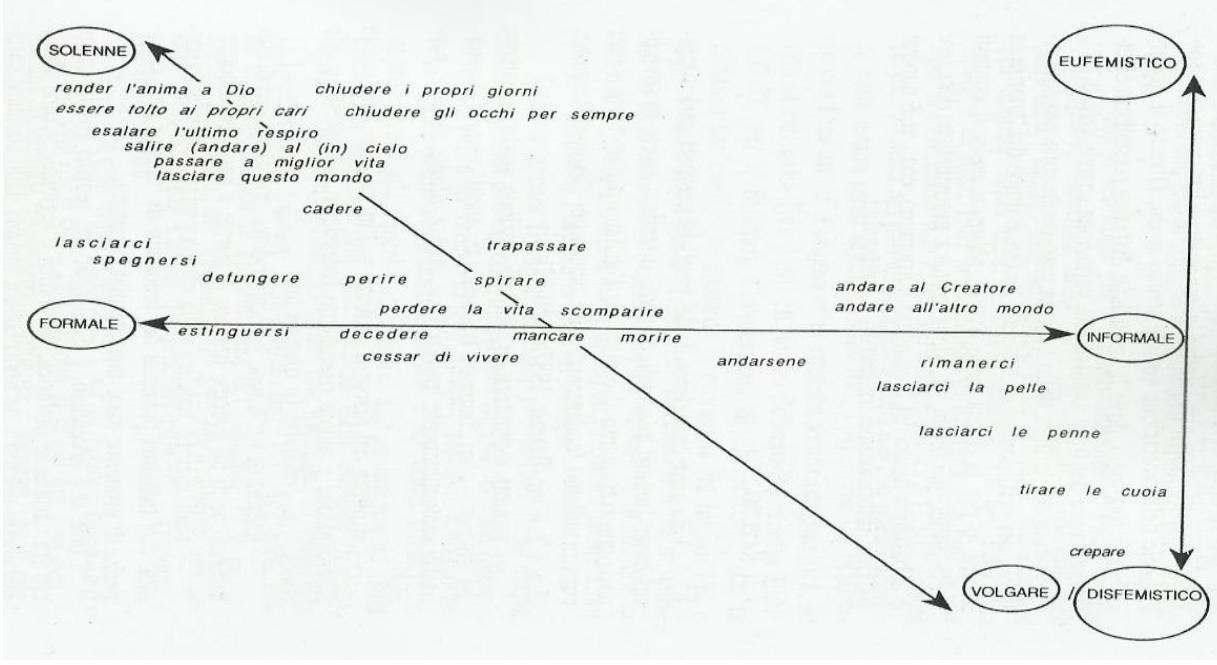

Figura 1: Esquema de Berruto para sinônimos do verbo "morire". 
No esquema acima é apresentada a colocação aproximativa, na competência e no sentimento linguístico de quem escreve, de uma série de expressões (termos e paráfrases) que designam o verbo "morire". Neste esquema os termos e paráfrases são colocados ao longo de três eixos que servem para determinar o registro: formal em oposição a informal (oposição que constitui a dimensão central para a definição do registro), solene em oposição a vulgar (que trata de efeitos de significados conotativos) e, finalmente, eufemístico em oposição a disfemístico (representa a chave interpretativa da maneira em que é realizada a expressão de um significado).

Na próxima seção deste trabalho será explicitada a metodologia empregada neste estudo para verificar se, além de conhecerem o significado dos termos e paráfrases usados por Berruto como sinônimos de "morire", os alunos de dois cursos de italiano da Faculdade de Letras da Universidade de São Paulo conheciam também os contextos em que tais termos e paráfrases deveriam ser usados (ou seja, se além da parte linguística, tais alunos eram conscientes também da parte pragmática da língua, mais especificamente de sua dimensão diafásica).

\section{METODOLOGIA}

Inicialmente foi pensado em pedir que os alunos inserissem as várias expressões sinônimas do verbo "morire" ao longo dos três eixos propostos por Berruto (1993), ou seja, ao longo dos eixos formal/informal, solene/vulgar e eufemístico/disfemístico. Os alunos receberiam o esquema proposto por Berruto vazio e deveriam inserir nele as expressões dadas:

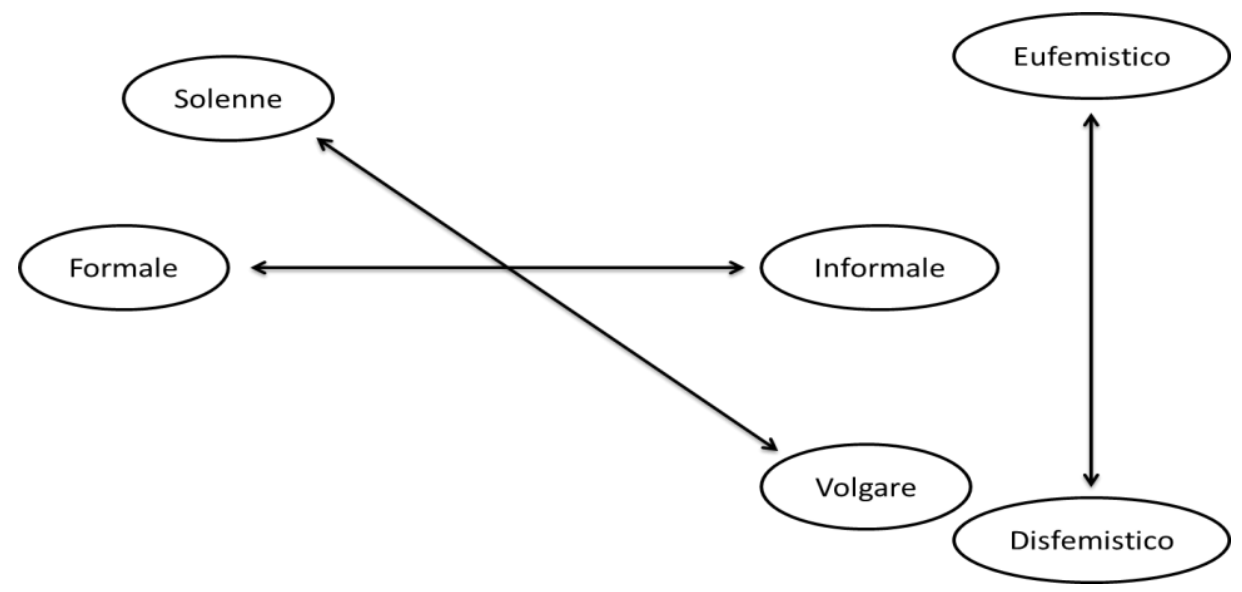

Figura 2: Esquema que os aprendizes deveriam preencher com as expressões propostas por Berruto. 
Entretanto, após uma análise da dificuldade de preencher um esquema tão complexo (devemos levar em consideração que o próprio Berruto indica que a colocação que faz é uma colocação aproximativa), foi decidido que seria levada em consideração apenas a oposição formal/informal, a qual constitui, como já se disse antes, a dimensão central para a definição do registro. Dessa forma, o esquema base seria o seguinte:

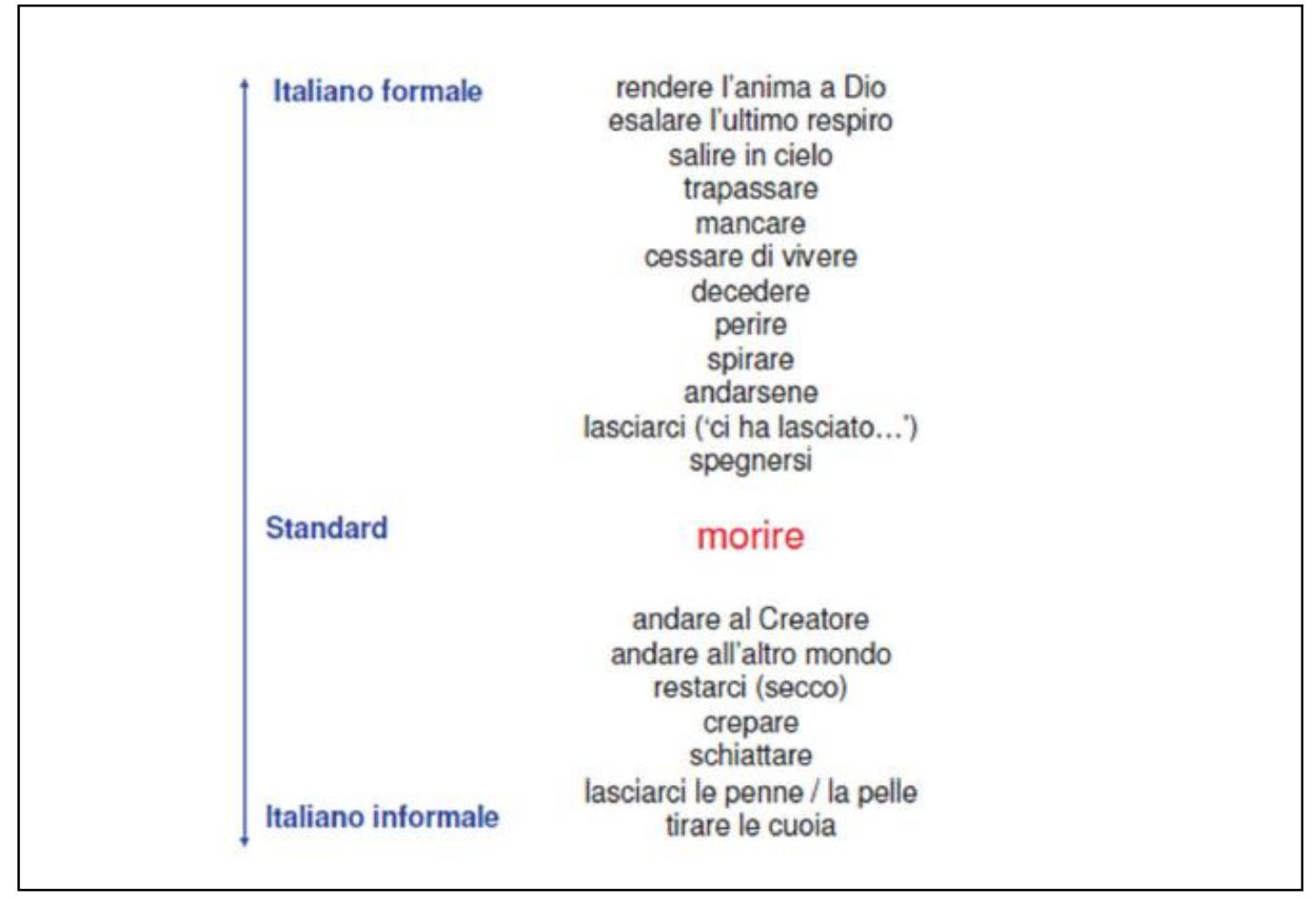

Figura 3: Escala de formalidade com os termos e paráfrases que designam o verbo "morire"

Foram então excluídos do esquema os termos e as expressões escolhidas por Berruto para que os aprendizes os inserissem levando em consideração a escala de formalidade (FIG. 4).

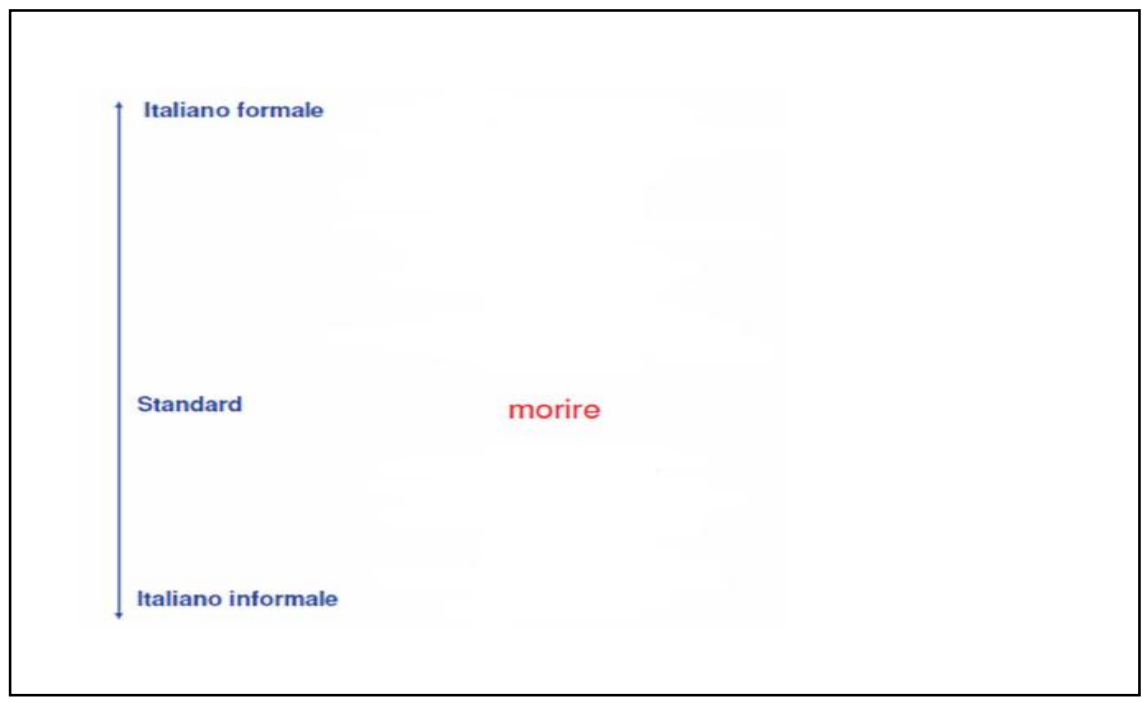

Figura 4: Continuum formal/informal que deveria ser preenchido com os sinônimos de "morire" 
As duas turmas do curso de Letras da USP que preencheram a escala de formalidade com os sinônimos de "morire" foram as turmas de Leitura e Compreensão de Textos e Língua Italiana II $^{7}$.

Antes que fosse pedido que os aprendizes de italiano preenchessem a escala de formalidade com os vários registros de "morire" foi dada uma aula de 1 hora e 20 minutos aos alunos sobre as dimensões de variação das línguas. A aula dada teve como objetivo familiarizar os alunos com a terminologia usada e mostrar-lhes a importância e a complexidade da pragmática quando se aprende uma língua estrangeira. Foram dados exemplos de inadequação no uso de algumas expressões italianas (ainda que a gramática estivesse correta) e de como situações desse tipo fazem com que exista um certo constrangimento por parte dos participantes da interação ${ }^{8}$.

$\mathrm{Na}$ primeira turma (Leitura e Compreensão de Textos) o número de alunos presentes foi de 6 alunos, enquanto na segunda turma (Língua Italiana II) o número de presentes foi de 4 .

Dada a aula sobre as dimensões de variação das línguas, os alunos receberam uma lista com as várias expressões que designam o verbo "morire" e, após esclarecidas algumas dúvidas de vocabulário foi pedido que eles inserissem tais expressões ao longo da escala recebida, com expressões que iam da mais formal à mais informal. A escala foi preenchida por 10 alunos e por um doutorando ${ }^{9}$ em Língua, Literatura e Cultura Italianas que estava presente nas aulas das turmas devido a sua participação no Programa de Aperfeiçoamento de Ensino (PAE) ${ }^{10}$ da USP.

Após o preenchimento da escala, foi mostrado aos alunos o esquema simplificado preenchido (FIG. 3) para que pudessem compará-lo aos esquemas que fizeram e verificar se eram semelhantes ou não. Em seguida foi mostrado aos alunos também o esquema original de Berruto (FIG. 1) para que os alunos pudessem constatar como a pragmática é

\footnotetext{
${ }^{7}$ Os alunos destas turmas haviam estudado a língua italiana há 3 e 1 ano respectivamente.

${ }^{8} \mathrm{Um}$ dos exemplos dados foi o de uma aluna de um curso livre de italiano que, ao passar algumas semanas na Itália a passeio e escutar a expressão "In culo alla balena", voltou ao Brasil e, quando queria desejar boa sorte a sua professora de italiano, ao invés de usar a expressão padrão "in bocca al lupo", usou a expressão que havia escutado durante sua viagem. A professora, surpresa, explicou à aluna que a expressão "in culo alla balena" tinha, sim, o mesmo significado de "in bocca al lupo", mas que, ao contrário de "in bocca al lupo" não era adequada à grande maioria dos contextos e que deveria ser utilizada em situações muito informais e entre amigos bastante próximos, por exemplo.

${ }^{9}$ Este aluno está em seu terceiro ano de doutorado em Língua, Literatura e Cultura Italianas e estuda a língua italiana há 10 anos.

${ }^{10}$ O PAE destina-se exclusivamente a alunos de pós-graduação matriculados na Universidade de São Paulo nos cursos de mestrado e doutorado e consiste de duas etapas: Preparação Pedagógica e Estágio Supervisionado em Docência.
} 
mais complexa e importante do que se costuma pensar, ou seja, não basta saber falar uma língua no sentido de conhecer suas palavras, sua estrutura sintática e a pronúncia de seus sons. Para falar realmente uma língua é preciso saber quando usar uma palavra ou expressão. É preciso adequar a linguagem aos vários contextos e para isso precisamos estar atentos a mais do que simplesmente a conjugação dos verbos ou à pronúncia correta das palavras.

Explicitada a metodologia empregada neste trabalho, passa-se na próxima seção à apresentação dos resultados obtidos bem como à análise desses resultados.

\section{APRESENTAÇÃO E ANÁLISE DOS DADOS}

As 11 escalas de formalidade preenchidas pelos alunos das turmas Leitura e Compreensão de Textos e Língua II e pelo doutorando em Língua, Literatura e Cultura Italianas foram analisadas somente em relação à oposição formal/informal. Inicialmente pensou-se em fazer a análise levando em consideração a posição dos termos e expressões ao longo da escala de formalidade, mas após refletir sobre o fato de que até para um falante nativo é difícil decidir, por exemplo, se uma expressão é pouco mais formal ou informal que outra ${ }^{11}$, foi decidido que a análise seria feita da seguinte forma: se os alunos colocassem as expressões consideradas formais por Berruto na parte formal e as expressões informais na parte informal da escala, o resultado seria considerado adequado. Tal decisão foi tomada porque saber escolher expressões formais para contextos formais e expressões informais para contextos informais (mesmo que uma expressão seja mais ou menos formal que outra expressão formal) já indica uma ótima competência pragmática por parte dos aprendizes.

As respostas dos alunos foram digitadas e analisadas automaticamente. Como este é um estudo piloto, as respostas não são numerosas e poderiam ter sido analisadas manualmente, mas pensando em trabalhos posteriores, foi decidido que a análise seria conduzida através da planilha Excel apresentada na FIG. 5:

\footnotetext{
${ }^{11}$ Exemplo do Português Brasileiro: "bater as botas" é mais ou menos informal que "vestir o paletó de madeira"?
} 


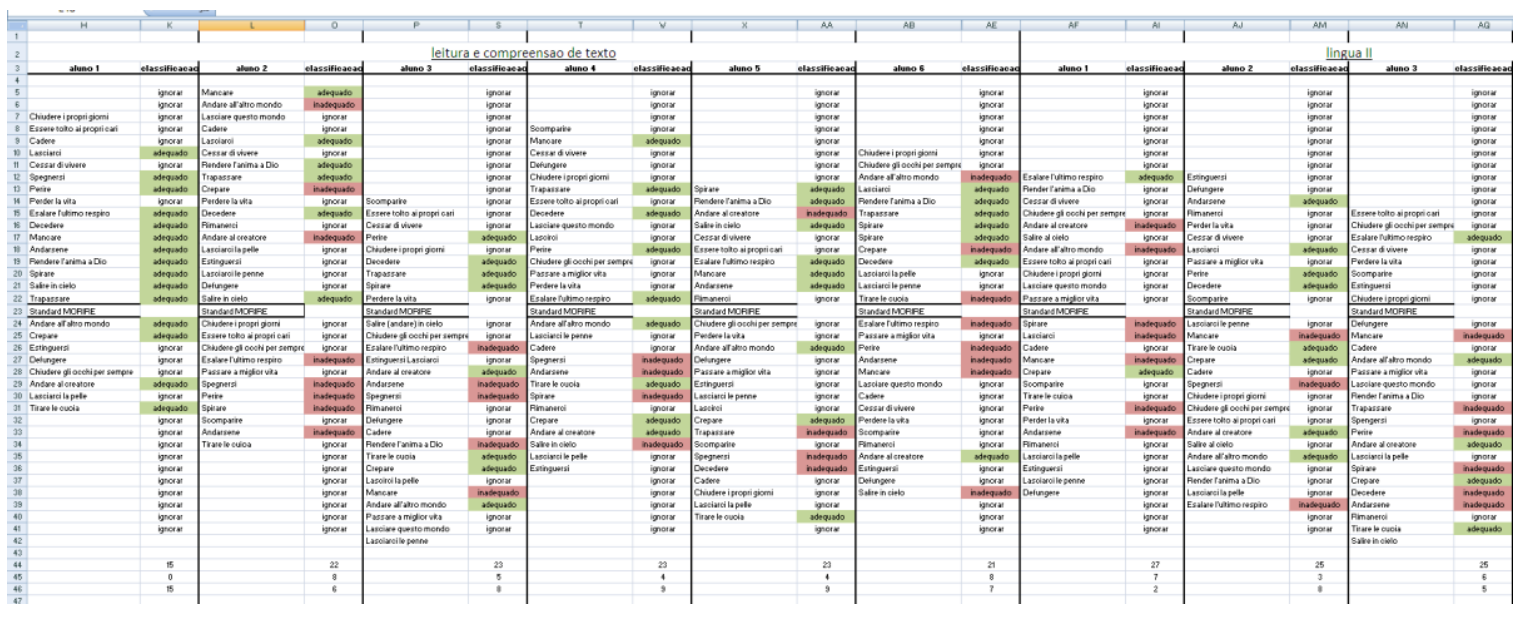

Figura 5: Planilha Excel com a análise dos esquemas montados pelos alunos

$\mathrm{Na}$ figura acima, a etiqueta "ignorar" é colocada na frente das expressões que estavam presentes no esquema dos alunos (e também no esquema de Berruto apresentado na FIG. 1) mas não estavam presentes no esquema simplificado escolhido posteriormente (FIG. 3) e portanto não deveriam ser analisadas. A etiqueta "inadequado" foi colocada na frente de expressões formais colocadas pelos alunos na parte de expressões informais e vice-versa. A etiqueta "adequado" foi colocada na frente de expressões colocadas pelos alunos adequadamente na área de expressões formais ou informais.

Entre os alunos da disciplina "Leitura e compreensão de textos", a média de expressões colocadas adequadamente nas áreas de expressões formais e informais foi de 9 , enquanto entre os alunos da disciplina "Língua II" a média de expressões colocadas adequadamente foi de 4,5. O total de expressões colocadas em posição adequada pelo estudante de doutorado participante da pesquisa foi de 10 . O resumo dos resultados obtidos pode ser visto no quadro abaixo:

QUADRO 1 - Resumo dos resultados obtidos

\begin{tabular}{|l|l|l|l|}
\hline Turma & Participante & Inadequado & Adequado \\
\hline Doutorado & doutorando & 4 & 10 \\
\hline $\begin{array}{l}\text { Leitura e Compreensão } \\
\text { de Textos }\end{array}$ & Aluno 1 & 0 & 15 \\
\hline $\begin{array}{l}\text { Leitura e Compreensão } \\
\text { de Textos }\end{array}$ & Aluno 2 & 8 & 6 \\
\hline $\begin{array}{l}\text { Leitura e Compreensão } \\
\text { de Textos }\end{array}$ & Aluno 3 & 5 & 8 \\
\hline $\begin{array}{l}\text { Leitura e Compreensão } \\
\text { de Textos }\end{array}$ & Aluno 4 & 4 & 9 \\
\hline Leitura e Compreensão & Aluno 5 & 4 & 9 \\
\hline
\end{tabular}




\begin{tabular}{|l|l|l|l|}
\hline de Textos & & & \\
\hline $\begin{array}{l}\text { Leitura e Compreensão } \\
\text { de Textos }\end{array}$ & Aluno 6 & 8 & 7 \\
\hline Língua II & Aluno 1 & 7 & 3 \\
\hline Língua II & Aluno 2 & 3 & 8 \\
\hline Língua II & Aluno 3 & 6 & 5 \\
\hline Língua II & Aluno 4 & 9 & 3 \\
\hline
\end{tabular}

A seguir são apresentadas análises estatísticas dos dados colhidos. Todas as análises foram realizadas utilizando o software livre R. Nelas a turma da disciplina Leitura e Compreensão de Textos é indicada através da sigla LCT e a turma da disciplina Língua II através da sigla L2. O gráfico 1 apresenta a distribuição de todas as respostas em termos de fração de expressões que estão em concordância com a referência. As respostas da turma LCT, que possui aproximadamente 3 anos de experiência com a língua italiana, se encontram à esquerda da linha vertical vermelha e as respostas da turma L2, que possui aproximadamente 1 ano de experiência com a língua italiana, se encontram à direita. Os indivíduos foram numerados de 1 a 10 para facilitar a representação gráfica.

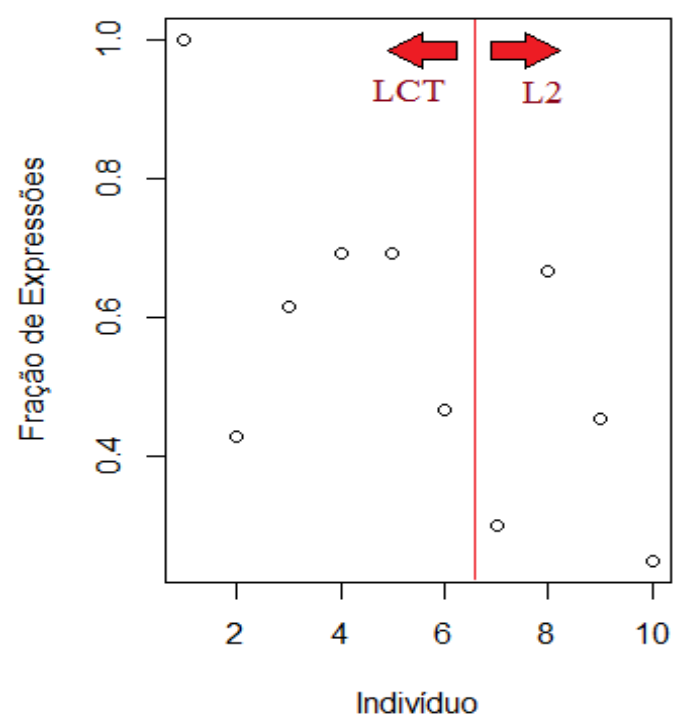

Gráfico 1: Fração de expressões de acordo com a referência dos indivíduos das duas turmas LCT e L2.

A maior parte dos resultados se encontra em torno de 50\%, variando de aproximadamente $25 \%$ a $70 \%$, exceto o indivíduo $\mathrm{n}^{\circ} 1$, que obteve uma taxa de concordância com a referência de 100\%. É também visível a maior quantidade de 
indivíduos presentes na turma LCT (6) em relação à turma L2 (4). O gráfico a seguir mostra o boxplot das duas turmas.

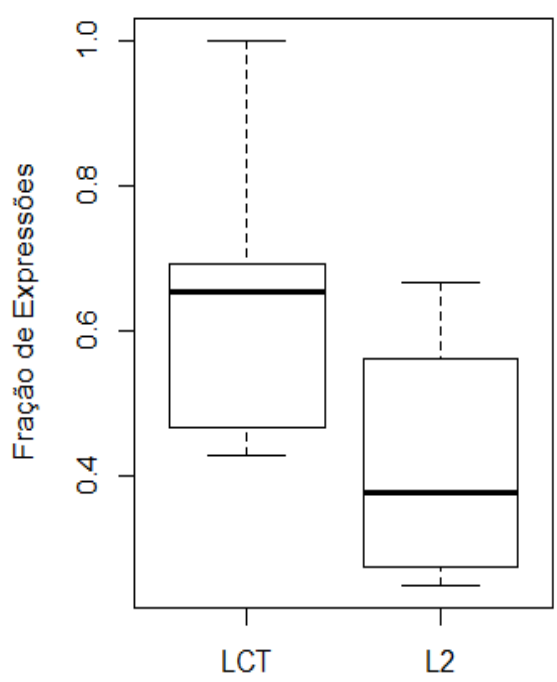

Gráfico 2: Boxplot mostrando a influência da turma na mediana e nos quartis da amostra

Analisando o gráfico 2, nota-se que a mediana dos indivíduos da turma LCT está acima da L2, indicando que possivelmente essa turma apresentou desempenho superior à turma L2. É importante observar que, como foram analisadas apenas duas alternativas possíveis para cada expressão (formal ou informal), é de se esperar que, mesmo classificando-as aleatoriamente, teríamos uma média de acerto, caso a quantidade de amostras fosse suficientemente grande, igual a 50\%. Essa afirmação é análoga à afirmação de que, em uma série relativamente grande de lançamentos de uma moeda, esperaríamos obter aproximadamente a mesma quantidade de caras e coroas. Com isso em mente, podemos concluir que o resultado médio de $41,8 \%$ da turma L2 foi abaixo de um resultado médio obtido aleatoriamente. Esse número a princípio pode parecer ilógico, mas uma análise estatística mais detalhada demonstra que esse valor foi fortemente afetado pela falta de indivíduos para o cálculo da média. Isso pode ser concluído realizando-se um teste de hipótese $^{12}$. Nesse teste, serão comparadas duas hipóteses: $\mathrm{H}_{0}$, que diz que a média é igual ou superior a $50 \%$ e $\mathrm{H}_{1}$, que diz que a média é inferior a 50\%. Para esse cálculo,

\footnotetext{
${ }^{12}$ Para aprofundamentos, ver Neto (1977)
} 
assumiremos uma significância ${ }^{13}$ de $5 \%$. O teste de hipótese pode ser realizado comparando as variáveis $t_{n-1}$ e $t_{G L ; \alpha}$ da seguinte forma:

\section{Tabela 1}

Testes de média com desvio padrão da população desconhecido

\begin{tabular}{|l|l|}
\hline Hipótese & Rejeita-se $H_{0}$ se \\
\hline$H_{0}: \mu=\mu_{0}$ & $t_{n-1}<-t_{n-1, \alpha}$ \\
$H_{1}: \mu<\mu_{0}$ & \\
\hline$H_{0}: \mu=\mu_{0}$ & $t_{n-1}>t_{n-1, \alpha}$ \\
$H_{1}: \mu>\mu_{0}$ & \\
\hline
\end{tabular}

Em que $t_{n-1}=\frac{\bar{x}-\mu_{0}}{s_{x} / \sqrt{n}}$ e $t_{n-1, \alpha}$ é extraído diretamente da distribuição de $t$ de Student. Dos parâmetros ainda indefinidos, $\bar{x}$ e $s_{x}$ são a média e o desvio padrão calculados da amostra extraída, n é o número de indivíduos e $\mu_{0}$ é a média que queremos testar ser verdadeira ou falsa. Para a turma L2, o teste de hipótese fica da seguinte forma:

$\left\{\begin{array}{l}H_{0}: \mu \geq 0,5 \\ H_{1}: \mu<0,5\end{array}\right.$

$t_{n-1}=-0,087$ e $t_{n-1, \alpha}=2,132$. Como $t_{n-1}>-t_{n-1, \alpha}$, para um nível de significância de $5 \%$, não podemos rejeitar $\mathrm{H}_{0}$. Isso significa que não é possível afirmarmos, com base nos dados disponíveis, que a média dessa população não é, efetivamente, maior ou igual a $50 \%$. Utilizando níveis de significância elevados, como $10 \%$ ou mesmo $20 \%$, ainda chegamos à mesma conclusão.

\footnotetext{
${ }^{13}$ A significância é a probabilidade de se rejeitar a hipótese H0 quando esta é verdadeira. É também conhecido na literatura como erro do tipo I. Os valores a serem utilizados dependem do grau de confiabilidade que se deseja ter dos cálculos, mas geralmente está entre $1 \%$ e 5\%. Nesse trabalho, como a amostra utilizada para os cálculos não foi muito numerosa, admitiremos uma significância que, eventualmente, será maior que os 5\%. Em trabalhos futuros, com uma quantidade maior de alunos, será possível admitir significâncias mais restritas.
} 
Foi realizado um teste de hipótese para verificar qual o nível de significância dos resultados encontrados para a turma LCT, cuja média foi de 64,9\%. É importante realizar esse teste, já que a amostra utilizada para a análise é extremamente reduzida. A hipótese nula $\mathrm{H}_{0}$ considera que os resultados foram obtidos aleatoriamente, ou seja, que a média é igual a 50\%. A hipótese $\mathrm{H}_{1}$ considera que a média é acima de 50\%, ou seja, que os anos de estudos dos alunos da turma LCT influenciaram positivamente nos resultados obtidos.

$\left\{\begin{array}{l}H_{0}: \mu=0,5 \\ H_{1}: \mu>0,5\end{array}\right.$

$t_{n-1}=1,78$ e $t_{n-1, \alpha}=2,015$, para um nível de significância de 5\%. Ou seja, com esse grau de certeza, não se pode rejeitar a hipótese nula, o que possivelmente seria evitado se mais dados fossem coletados da amostra. Apesar disso, aumentando o nível de significância para 6,3\%, um valor ainda razoável dada a amostra utilizada, chegamos à conclusão de que $t_{n-1}>t_{n-1, \alpha}$. Conclui-se portanto que, com um nível de significância de $6,3 \%$, podemos rejeitar a hipótese nula, ou seja, a média populacional é maior que $50 \%$.

Apresentados os resultados obtidos a partir das respostas dos alunos participantes da pesquisa, passa-se na próxima seção às considerações finais do estudo.

\section{CONSIDERAÇÕES FINAIS}

Apesar da quantidade relativamente pequena de indivíduos utilizados na amostra, comparando diretamente as médias obtidas entre as duas turmas, foi notado um aumento substancial na quantidade de expressões em conformidade com a referência de Berruto (de 41,8\% para 64,9\%, um aumento relativo de 55,4\%) da turma L2 para a turma LCT. Esse fato evidencia, para a amostra considerada, a melhora da competência pragmática dos aprendizes com o aumento de anos de estudo da língua italiana.

Outro fato interessante é que não há evidências de que a exposição que a turma L2 teve à língua italiana foi suficiente para que se desenvolvesse qualquer competência pragmática relacionada à experiência descrita. É importante salientar que a falta de alunos utilizados para os cálculos dificulta conclusões mais generalistas. 
Como próximos passos na direção de conclusões estatísticas mais robustas, é mandatória a realização do teste com mais alunos, aumentando assim a amostragem da população de interesse.

\section{REFERÊNCIAS}

BERRETTA, M. Il parlato italiano contemporaneo. In: SERIANNI, L; TRIFONE, P. (Orgs.). Storia della lingua italiana: Scritto e Parlato. Torino: Giulio Einaudi, 1994. v. II, p. 239-270.

BERRUTO, G. Sociolinguistica dell'italiano contemporaneo. Roma: La Nuova Italia Scientifica, 1987.

. Varietà diamesiche, diastratiche, diafasiche. In: SOBRERO, A. A. (Org.). Introduzione all'italiano contemporaneo: La variazione e gli usi. Bari: Laterza, 1993. V. II, p. 37-87.

HALLIDAY, M. A. K. Spoken and written language. Victoria: Deakin University Press, 1985.

MANZONI, A. I promessi sposi. Milão: Mondadori, 1927.

NETO, P. L. O. C. Estatística. São Paulo: Edgard Blucher, 1977. 